\title{
High Incidence of Hepatitis B Infection-Associated Cirrhosis and Hepatocellular Carcinoma in the Southeast Asian Patients with Portal Vein Thrombosis
}

\author{
Korn Lertpipopmetha and Chirayu U Auewarakul ${ }^{*}$
}

\begin{abstract}
Background: Portal vein thrombosis (PVT) is a rare condition associated with serious morbidity and mortality. The objective of this study was to determine the frequency, clinical presentations, and risk factors of PVT from the set of data firstly collected among the Southeast Asian population.

Methods: A retrospective study was undertaken to identify patients diagnosed with thrombosis of the portal system and other abdominal veins. The hospital medical records were retrieved based on the selected ICD-10 codes. Clinical presentations were collected and risk factors determined.
\end{abstract}

Results: From 2000-2009, 467 hospital charts with designated ICD-10 codes of 181, 182.2, 182.3, 182.8, 182.9, or K55.0 were identified. PVT (181) was the most common thrombosis (194 cases, 41.54\%). The majority of PVT patients were males (65\%), older than 40 years (75\%), and presented with abdominal distension/ascites (69\%), splenomegaly (54.6\%), and abdominal pain (50.5\%). Overall, the predominant risk factor was hepatocellular carcinoma (HCC) (52.5\%), followed by liver cirrhosis without cancer (9.3\%), abdominal infection/inflammation (9.3\%), cholangiocarcinoma (8.2\%), and abdominal intervention (7.7\%). In young patients, abdominal interventions including umbilical catheterization (23.1\%) and hepatectomy (7.7\%) were the most frequent risks whereas in older cases, primary hepatobiliary cancer and cirrhosis (78\%) were the major risks. Liver metastases from other organs were infrequently found. Chronic hepatitis B virus (HBV) infection was the main etiology associated with cirrhosis/ HCC leading to PVT in this cohort. A third of the older PVT patients (age $\geq 40$ ) had HBV and very few carried hepatitis $\mathrm{C}$ virus ( $\mathrm{HCV}$ ) whereas none of the young PVT patients (age <20) had HBV or HCV. A variety of abdominal infections/inflammations were also found including liver abscess, splenic abscess, cholangitis, cholecystitis, pancreatitis, omphalitis, and abdominal tuberculosis. Single cases of systemic lymphangiomatosis and KlippelTrénaunay vascular malformation syndrome were also identified. Other thrombophilic conditions such as myeloproliferative neoplasms, paroxysmal nocturnal hemoglobinuria, protein $\mathrm{S}$ deficiency, and anti-phospholipid syndrome were rarely encountered.

Conclusion: HBV is the major risk of PVT in the Southeast Asian population. Several risk factors identified in this population have rarely been described and some are remarkably different from those reported in the West. Host and environmental factors may play a causal role in the initiation and development of PVT in various ethnicities and geographic locations.

Keywords: portal vein thrombosis, incidence, risk factors, cirrhosis, hepatocellular carcinoma, HBV infection, Southeast Asia

\footnotetext{
* Correspondence: chirayuaue@yahoo.com

Department of Medicine, Faculty of Medicine Siriraj Hospital, Mahidol

University, Bangkok, Thailand
} 


\section{Background}

Portal vein thrombosis (PVT) is considered a rare clinical and pathological entity $[1,2]$. Thrombus formation usually begins in the portal vein and sometimes extends to other branches of the portal system such as splenic vein or mesenteric vein $[1,3,4]$. The involved blood vessels can be partially or totally occluded resulting in increased portal venous outflow resistance from narrowing or obstructed blood vessel lumens $[1,3,4]$. As thrombosis usually occurs gradually giving time for the development of cavernous transformation as a result of periportal collateralization around the occluded portal vein, most patients are asymptomatic and do not seek medical attention [2-4]. However, obvious signs of portal hypertension such as splenomegaly, ascites, and massive hemorrhage from esophageal and gastric varices could also be found [1-6]. In the acute setting of moderate to severe thrombus occlusion, abdominal pain may be the striking presentation [2-4,6,7].

The prevalence of PVT is not well-defined due to its rarity and initial asymptomatic nature. Nevertheless, transient occlusion of the portal system is increasingly being recognized during the diagnostic course of various acute and chronic abdominal problems such as appendicitis, cholecystitis, cholangitis, pancreatitis, and other intra-abdominal infections by ultrasonography [6,7]. A proportion of patients with portal hypertension were also found coincidentally to have a thrombus in the portal system [1-4,6,8]. In a study of 701 hospitalized patients with cirrhosis who underwent routine ultrasound screening, PVT could be identified in $11 \%$ of the cases [3]. The largest series was a retrospective review of 23,796 autopsies which revealed the prevalence of PVT of $1 \%$ [1].

Since PVT is an uncommon and under-recognized disorder and its true prevalence is not presently established, it was of much interest to conduct a study to explore the frequency, clinical presentations, and risk factors of PVT at one of the largest hospitals in Southeast Asia. During a 10-year period, we were able to find 194 PVT cases and the majority of them presented with a classical sign of portal hypertension and advanced symptoms. Interestingly, the identifiable risk factors appeared to be mostly associated with hepatitis $B$ virus $(\mathrm{HBV})$ infection which is prevalent in this region. The fact that $\mathrm{HBV}$-associated cirrhosis and hepatocellular carcinoma (HCC) are the predominant risks for PVT is strikingly different from the major risk factors in the Western reports. Other diseases that have rarely been described were also discovered in this series including Klippel-Trénaunay syndrome [9], systemic lymphangiomatosis [10], and abdominal tuberculosis [6].

\section{Methods}

This study was a retrospective analysis undertaken at Siriraj Hospital which is the largest hospital in Thailand comprising of more than 2,500 inpatient beds and more than 2 million outpatient visits a year. Patients diagnosed with thrombosis of the portal system and other abdominal veins from January 2000 to December 2009 were identified through the hospital's computerized medical records based upon the Tenth Revision of the International Statistical Classification of Diseases and Related Health Problems (ICD-10) coding system http:// www.who.int/classifications/icd/en/. The study was approved by the Faculty of Medicine Siriraj Hospital Ethical Committee.

The following data were extracted from the medical records: demographic data (age and gender), clinical presentations (abdominal pain, abdominal distension, loss of appetite, nausea, vomiting, diarrhea, weight loss, splenomegaly, fever, jaundice, ascites, and gastrointestinal hemorrhage), complications (esophageal and gastric varices, variceal hemorrhage, portal hypertensive gastropathy, and ascites), extension of the thrombus (main, right or left branch of portal vein, mesenteric vein, splenic vein, vena cava), imaging methods used to diagnose PVT (ultrasound with or without Doppler, computed tomography $(\mathrm{CT})$, magnetic resonance imaging (MRI) or magnetic resonance venography (MRV)), and hepatitis serology (HBV and hepatitis $\mathrm{C}$ virus $(\mathrm{HCV})$ ). Diagnosis of portal hypertensive gastropathy and grading of esophageal- and gastric varices was made by means of esophago-gastro-duodenoscopy (EGD). Owing to the severity of cancer and cirrhosis, the patients were classified into 2 groups: group 1) patients with cancer or cirrhosis and group 2) patients without cancer and cirrhosis. Patients were also categorized into 4 groups according to respective ages: group 1) $<20$ years, group 2) $\geq 20$ to 40 years, group 3) $\geq 40$ to 60 years, and group 4) $\geq 60$ years. Statistical analyses of continuous variables (mean, standard deviation (SD), and range) and categorical variables (number and percentage) were performed. A p-value was calculated when indicated.

\section{Results}

\subsection{Incidence of PVT and other abdominal vein thrombosis}

From 2000-2009, 467 hospital charts with designated ICD-10 codes of 181 , I82.2, I82.3, I82.8, I82.9, or K55.0 were identified and extracted from the hospital system. PVT (I81) was the most commonly identified thrombosis (194 cases, 41.5\%) among all abdominal venous thrombosis as shown in Table 1.

Table 2 delineates the distribution of thrombosis in the portal system in the 194 patients diagnosed with 
Table 1 Frequency of abdominal vein thrombosis

\begin{tabular}{lc}
\hline Thrombosis classified based on ICD-10 codes & $\begin{array}{c}\text { No. of cases } \\
\text { (\%) }\end{array}$ \\
\hline Portal vein thrombosis (I81) & $194(41.5)$ \\
Mesenteric vein thrombosis (K55.0) & $18(3.9)$ \\
Thrombosis of vena cava (I82.2) & $81(17.3)$ \\
Thrombosis of renal vein (I82.3) & $18(3.9)$ \\
Thrombosis of other specified vein (182.8) & $96(20.6)$ \\
Thrombosis of unspecified vein (182.9) & $52(11.1)$ \\
Thrombosis of isolated splenic vein & $3(0.6)$ \\
Thrombosis of vena cava + renal vein & $3(0.6)$ \\
Thrombosis of vena cava + other specified veins & $1(0.2)$ \\
Thrombosis of vena cava + renal vein + other & $1(0.2)$ \\
specified veins & \\
Total cases in this study & $\mathbf{4 6 7}(100)$ \\
\hline
\end{tabular}

PVT. Mainly, the portal vein was solely involved (145 cases, $74.7 \%)$. Other branches were less frequently involved including splenic vein, superior mesenteric vein, inferior mesenteric vein, and vena cava. The first diagnosis of PVT was established by ultrasonography (33 cases, 17\%), Doppler ultrasonography (13 cases, $6.7 \%)$, CT (139 cases, $71.6 \%)$, MRI ( 2 cases, $1 \%)$, and MRV (7 cases, 3.6\%).

\subsection{Clinical presentations of patients with PVT}

Table 3 shows the demographic data and clinical presentations of 194 PVT cases. These patients were predominantly males (126 cases, 65\%) and aged older than 40 years $(74.8 \%)$. The mean age at the time of admission was 50 (range, $0.2-82.9$ years) and the affected male cases were older than the affected female cases (52.4 \pm 15.7 SD vs $46.2 \pm 20.8$ SD, respectively). Only $6.7 \%$ of the cases were aged younger than 20 and $33 \%$ were older than 60 . The most common clinical presentation in the younger patients, age $<20(84.6 \%)$ and age $20-39$ (61.1\%), was splenomegaly whereas in the older patients, age $40-60(66.7 \%)$ and age $>60(76.6 \%)$, was abdominal distension/ascites. Abdominal distension/ascites was the most common clinical presentation in both males (43.8\%) and females (25.3\%).

Table 2 Distribution of thrombosis in 194 patients with PVT

\begin{tabular}{lc}
\hline Site of thrombotic involvement & No. of cases (\%) \\
\hline Portal vein only & $145(74.7)$ \\
Porto-mesenteric (SMV) & $12(6.2)$ \\
Porto-mesenteric (IMV) & $0(0)$ \\
Porto-venacaval & $2(1)$ \\
Porto-splenic & $16(8.2)$ \\
Porto-spleno-mesenteric (SMV) & $19(9.8)$ \\
Porto-spleno-mesenteric (IMV) & $1(0.5)$ \\
\hline
\end{tabular}

"Imaging modalities for the first diagnosis of PVT included ultrasonography (17\%), Doppler ultrasonography (6.7\%), CT (71.6\%), MRI (1\%), and MRV (3.6\%).
Table 3 Clinical presentations of 194 patients with PVT

\begin{tabular}{ll}
\hline Sex (M:F) & $126: 68$ \\
Mean age \pm SD (range) & $50.2 \pm 17.9(0.2-82.9)$ \\
- Male & $(\mathrm{n}=126) 52.4 \pm 15.7(1-80.8)$ \\
- Female & $(\mathrm{n}=68) 46.2 \pm 20.8(0.2-82.9)$ \\
Age $\mathbf{2 0}$ (no. of cases, \%) & $13(6.7)$ \\
Age 20-39 (no. of cases, \%) & $36(18.6)$ \\
Age 40-60 (no. of cases, \%) & $81(41.8)$ \\
Age >60 (no. of cases, \%) & $64(33)$ \\
\hline Clinical presentations & No. of cases (\%) \\
$\quad$ Asymptomatic & $2(1)$ \\
$\quad$ Abdominal distension/ascites & $134(69.1)$ \\
Abdominal pain & $98(50.5)$ \\
Jaundice & $70(36.1)$ \\
Fever & $26(13.4)$ \\
Splenomegaly & $106(54.6)$ \\
Hemorrhage & $35(18)^{*}$ \\
Loss of appetite & $56(28.9)$ \\
Weight loss & $63(32.5)$ \\
Nausea & $32(16.5)$ \\
Vomiting & $25(12.9)$ \\
Diarrhea & $14(7.2)$ \\
\hline
\end{tabular}

*hematemesis (10), melena (6), hematochezia (3), hematemesis and melena (11), hematemesis and hematochezia (3), melena and hematochezia (1), hematemesis, melena and hematochezia (1)

There were 144 PVT patients (105 males and 39 females) who were diagnosed with cancer or cirrhosis with a mean age at the time of diagnosis of $55.8 \pm 14.3$ (range, 1.9-82.9 years). Fifty PVT patients (21 males and 29 females) with a mean age of $34.2 \pm 17.7$ (range, 0.265.9 years) did not have detectable cancer and cirrhosis. There was no age difference between both genders. Seventy-eight percent of PVT patients with cancer or cirrhosis presented with abdominal distension/ascites followed by splenomegaly (50.7\%), abdominal pain (47.2\%), jaundice (47.9\%), weight loss (39.6\%), loss of appetite $(35.4 \%)$, nausea (16.7\%), hemorrhage (14.6\%), fever (13.9\%), vomiting (13.2\%), and diarrhea (7.6\%), and $1.4 \%$ of these patients were asymptomatic. Sixty-six percent of PVT patients without cancer and cirrhosis presented with splenomegaly followed by abdominal pain (60\%), abdominal distension/ascites (44\%), hemorrhage (28\%), nausea (16\%), vomiting (12\%), weight loss (12\%), fever $(12 \%)$, loss of appetite (10\%), diarrhea (6\%), and jaundice $(2 \%)$. None of the patients in the latter group was asymptomatic.

\subsection{Risk factors associated with PVT}

Risk factors for PVT could be established in the majority of cases (176 cases, 90.7\%). Eighty-four cases (43.3\%) had a single risk factor, 89 cases $(45.9 \%)$ had two risk factors, and 3 cases (1.5\%) had three risk factors. Table 4 summarizes the risk factors identified to be associated 
Table 4 Risk factors associated with PVT

\begin{tabular}{|c|c|}
\hline Malignancy & $126(65)$ \\
\hline \multicolumn{2}{|c|}{ HCC (102), CCA (16), pancreatic CA (3), gallbladder CA (1), hepatoblastoma (1), ovarian CA (1), secondary malignant neoplasm of liver (2) } \\
\hline Cirrhosis* & $98(50.5)$ \\
\hline \multicolumn{2}{|c|}{$\begin{array}{l}\text { HBV (38), HCV (12), Alcohol (15), HBV+HCV (2), HBV+alcohol (8), HCV+alcohol (3), cryptogenic (19), autoimmune (1) [Child-Pugh Class: A (29), B (30), } \\
\text { (30), unknown (9)] }\end{array}$} \\
\hline Abdominal intervention & $15(7.7)$ \\
\hline \multicolumn{2}{|c|}{$\begin{array}{l}\text { Umbilical catheterization (5), splenectomy (2), cholecystectomy (5), hepatectomy (1), percutaneous transhepatic biliary drainage (PTBD) (1), Whipple } \\
\text { operation with revised hepatojejunostomy and T-tube (1) }\end{array}$} \\
\hline Abdominal inflammation/infection & $18(9.3)$ \\
\hline \multicolumn{2}{|c|}{ Pancreatitis (3), liver abscess (4), cholangitis (4), splenic abscess (1), cholecystitis (1), omphalitis (1), abdominal tuberculosis (1), sepsis (3) } \\
\hline Bone marrow (BM) disorders & $9(4.6)$ \\
\hline \multicolumn{2}{|c|}{ Polycythemia vera (3), primary myelofibrosis (2), essential thrombocytosis (1), paroxysmal nocturnal hemoglobinuria (2), acute myeloid leukemia (1) } \\
\hline Hereditary coagulation defects & $1(0.5)$ \\
\hline \multicolumn{2}{|l|}{ Protein S deficiency (1) } \\
\hline Anti-phospholipid syndrome & $1(0.5)$ \\
\hline Oral contraceptive pills & $4(2)$ \\
\hline Others** & $2(1)$ \\
\hline Idiopathic causes & $18(9.3)$ \\
\hline
\end{tabular}

*Include cases with hepatocellular carcinoma (HCC) (79) and cholangiocarcionoma (CCA) (1)

** Klippel-Trénaunay syndrome (1), splenic lymphangiomatosis (1)

with PVT in this study cohort. The most common cause was cancer (126 cases, 65\%) followed by cirrhosis (98 cases, 50.5\%), abdominal intervention (15 cases, 7.7\%), abdominal inflammation/infection (18 cases, 9.3\%, and bone marrow disorders ( 9 cases, $4.6 \%$ ). The most common type of cancer was hepatocellular carcinoma (HCC) $(102 / 126,81 \%)$ followed by cholangiocarcinoma (CCA) $(16 / 126,12.7 \%)$, pancreatic carcinoma $(3 / 126,2.4 \%)$, and liver metastasis $(3 / 126,2.4 \%)$. One case each of gall bladder carcinoma, hepatoblastoma, and ovarian carcinoma was also found. A variety of infections were found to be associated with PVT including pancreatitis (3), liver abscess (4), cholangitis (4), splenic abscess (1), cholecystitis (1), omphalitis (1), and abdominal tuberculosis (1).
Risk factors are categorized based on the patients' age and gender as shown in Table 5. The most common risk factor in the patients aged $<20$ was abdominal interventions ( 3 umbilical catheterization and 1 hepatectomy) which was found in $30.8 \%$ of the cases. Almost half of the young cases had unidentifiable risk factors $(46.2 \%)$. In contrast, cancer was the predominant risk factor in the patients aged 20-39 (38.9\%), aged 40-60 (69.1\%), and aged $>60(86 \%)$. More PVT male cases had cancer than female PVT cases $(74.6 \%$ vs 47.1\%). Cirrhosis was more frequently found in males than females $(61.9 \%$ vs $29.4 \%)$. A higher proportion of females had unidentifiable risks than males $(16.2 \%$ vs $5.6 \%$, respectively).

Table 5 Risk factors for PVT according to age and gender

\begin{tabular}{|c|c|c|c|c|c|c|c|}
\hline \multirow[t]{3}{*}{ Risk factors* } & \multirow[t]{2}{*}{ All patients } & \multicolumn{4}{|c|}{ Age range (years) } & \multicolumn{2}{|c|}{ Gender } \\
\hline & & $<20$ & 20-39 & $40-60$ & $>60$ & Male & Female \\
\hline & $\begin{array}{c}N(\%) \\
194(100)\end{array}$ & $\begin{array}{c}N(\%) \\
13(6.7)\end{array}$ & $\begin{array}{c}\mathrm{N}(\%) \\
36(18.6)\end{array}$ & $\begin{array}{c}N(\%) \\
81(41.8)\end{array}$ & $\begin{array}{c}N(\%) \\
64(33)\end{array}$ & $\begin{array}{c}N(\%) \\
126(65)\end{array}$ & $\begin{array}{c}N(\%) \\
68(35.1)\end{array}$ \\
\hline Cirrhosis & $98(50.5)$ & $1(7.7)$ & $6(16.7)$ & $52(64.2)$ & $39(60.9)$ & $78(61.9)$ & $20(29.4)$ \\
\hline Malignancy & $126(65)$ & $1(7.7)$ & $14(38.9)$ & $56(69.1)$ & $55(86)$ & $94(74.6)$ & $32(47.1)$ \\
\hline Abdominal intervention & $15(7.7)$ & $4(30.8)$ & $3(8.3)$ & $6(7.4)$ & $2(3.1)$ & $6(4.8)$ & $9(13.2)$ \\
\hline Abdominal inflammation or infection & $18(9.3)$ & $1(7.7)$ & $5(13.9)$ & 7 (8.6) & $5(7.8)$ & $7(5.6)$ & $8(11.8)$ \\
\hline BM disorders, protein S deficiency, and APS & $11(5.7)$ & $1(7.7)$ & $3(8.3)$ & $5(6.2)$ & $2(3.1)$ & $5(4)$ & $6(8.8)$ \\
\hline Oral contraceptive pills & $4(2)$ & $0(0)$ & $4(11.1)$ & $0(0)$ & $0(0)$ & $0(0)$ & $4(5.9)$ \\
\hline Others & $2(1)$ & $0(0)$ & $2(5.6)$ & $0(0)$ & $0(0)$ & $1(0.8)$ & $1(1.5)$ \\
\hline Idiopathic & $18(9.3)$ & $6(46.2)$ & $8(22.2)$ & $3(3.7)$ & $1(1.6)$ & $7(5.6)$ & $11(16.2)$ \\
\hline
\end{tabular}

$\mathrm{N}$, number of cases; BM, bone marrow; APS, anti-phospholipid syndrome

*Some patients had more than one risk factor. 
Table 6 Frequency of HBV and HCV infection in patients with PVT according to HCC/cirrhosis status, age, and gender

\begin{tabular}{|c|c|c|c|c|c|c|c|c|}
\hline \multirow[t]{3}{*}{ Risk factors* } & \multirow[t]{2}{*}{ PVT with HCC or cirrhosis } & \multirow[t]{2}{*}{ PVT without HCC and cirrhosis } & \multicolumn{4}{|c|}{ Age (years) } & \multicolumn{2}{|c|}{ Gender } \\
\hline & & & $<20$ & $20-39$ & $40-60$ & $>60$ & Male & Female \\
\hline & $\mathrm{N}(\%)$ & $\mathrm{N}(\%)$ & $\mathrm{N}(\%)$ & $\mathrm{N}(\%)$ & $\mathrm{N}(\%)$ & N (\%) & $\mathrm{N}(\%)$ & $\mathrm{N}(\%)$ \\
\hline HBV infection $^{a}$ & $51(42.1)$ & $2(2.7)$ & $0(0)$ & $9(0.25)$ & $27(33.3)$ & $17(26.6)$ & 49 (39) & $4(5.9)$ \\
\hline HCV infection ${ }^{b}$ & $17(14)$ & $1(1.4)$ & $0(0)$ & $0(0)$ & $13(16)$ & $5(7.8)$ & $12(9.5)$ & $6(8.8)$ \\
\hline HBV and HCV co-infection ${ }^{c}$ & $2(1.7)$ & $0(0)$ & $0(0)$ & $0(0)$ & $2(2.5)$ & $0(0)$ & $2(1.6)$ & $0(0)$ \\
\hline
\end{tabular}

${ }^{*} \mathrm{P}$ value between age groups $={ }^{\mathrm{a}} 0.091,{ }^{\mathrm{b}} 0.022,{ }^{\mathrm{c}} 0.420$

\subsection{Incidence of HBV and HCV infection in patients with} PVT

The frequency of HBV and HCV infections in patients with PVT according to the $\mathrm{HCC} /$ cirrhosis status, age, and gender is shown in Table 6. Increasing incidence of HBV infection was observed with increasing age. None of the young patients (aged <20) had HBV or HCV infections whereas about a third of older patients (aged 240) had HBV infection and less than $3 \%$ had HCV infection. More males with PVT were affected with HBV than females (39\% vs 5.9\%, respectively). PVT patients with HCC or cirrhosis $(51 / 121,42.1 \%)$, especially in patients aged $\geq 40(44 / 145,30.3 \%)$ had HBV infection as the most important risk factor. HCV infection $(17 / 121,14 \%)$ and HBV/HCV co-infection (2/121, $1.7 \%)$ were not as common as compared to HBV infection alone. Patients without cirrhosis or HCC had a very low frequency of HBV and HCV infections.

\subsection{Distribution of thrombus in PVT patients with or} without cirrhosis and cancer

Table 7 shows the branch distribution of thrombus according to age and gender. In the young patients aged $<20$ and 20-39 (79.4\%), the main branch was commonly affected whereas in the older patients, the right branch was slightly more affected than the left and the main branches. With respect to gender, the main and the right branches were commonly involved than the left branch in males $(64.8 \%$ and $65.6 \%$, respectively) whereas the main branch was slightly more affected than other branches in females (62.7\%). The most common distribution of thrombus in the patients with cancer and cirrhosis was the right branch whereas in the patients with cirrhosis only was the main branch. For patients without cancer and cirrhosis, the thrombus was equally distributed in all branches.

More patients in the cirrhosis only group had portomesenteric thrombus (SMV) (5/18) whereas almost half of the patients with bone marrow (BM) disorders, protein $\mathrm{S}$ deficiency, and anti-phospholipid syndrome (APS) had portosplenic thrombus (5/11). Two cases of portocaval thrombosis were caused by cancer (100\%). Portospleno-mesenteric (SMV) thrombus was more commonly found in cases without cancer or cirrhosis $(10 / 19$, $52.6 \%)$.

Table 7 Distribution of thrombus in the portal vein branches based on age and gender\#

\begin{tabular}{|c|c|c|c|c|c|}
\hline & Total & $\begin{array}{c}\text { Right Branch } \\
\mathrm{N}(\%) \\
112(61.9)\end{array}$ & $\begin{array}{c}\text { Left branch } \\
N(\%) \\
82(45.3)\end{array}$ & $\begin{array}{c}\text { Main } \\
\mathrm{N}(\%) \\
116(64.1)\end{array}$ & $\begin{array}{c}\text { Confluence } \\
N(\%) \\
10(5.5)\end{array}$ \\
\hline \multicolumn{6}{|l|}{ Age (years) } \\
\hline$<20$ & 10 & $4(40)$ & $2(20)$ & $7(70)$ & $0(0)$ \\
\hline $20-39$ & 34 & $17(50)$ & $12(35.3)$ & $27(79.4)$ & $1(2.9)$ \\
\hline $40-60$ & 75 & $47(62.7)$ & $41(54.7)$ & $43(57.3)$ & $5(6.7)$ \\
\hline$>60$ & 62 & $44(71)$ & $27(43.5)$ & $39(62.9)$ & $4(6.5)$ \\
\hline \multicolumn{6}{|l|}{ Gender } \\
\hline -Male & 122 & $80(65.6)$ & $57(46.7)$ & $79(64.8)$ & $7(5.7)$ \\
\hline -Female & 59 & $32(54.2)$ & $25(42.4)$ & $37(62.7)$ & $3(5.2)$ \\
\hline \multicolumn{6}{|l|}{ PVT with CA or cirrhosis } \\
\hline $\begin{array}{l}\text {-CA only } \\
\text {-Cirrhosis only }\end{array}$ & $\begin{array}{l}44 \\
15\end{array}$ & $\begin{array}{c}32(72.7) \\
9(60)\end{array}$ & $\begin{array}{l}17(38.6) \\
5(33.3)\end{array}$ & $\begin{array}{l}26(59.1) \\
13(86.7)\end{array}$ & $\begin{array}{l}1(2.3) \\
0(0)\end{array}$ \\
\hline -CA with cirrhosis & 80 & $52(65)$ & $43(53.8)$ & $43(53.8)$ & $5(6.3)$ \\
\hline \multicolumn{6}{|l|}{ PVT without CA and cirrhosis } \\
\hline -BM disorders and other risks & 8 & $6(75)$ & $7(87.5)$ & $6(75)$ & $1(12.5)$ \\
\hline -Others & 34 & $13(38.2)$ & $10(29.4)$ & $28(82.4)$ & $3(8.8)$ \\
\hline
\end{tabular}

${ }^{\#} 181$ cases had a complete description of involved branches by imaging studies 


\section{Discussion}

A variety of etiologic factors of PVT has previously been described including hereditary and acquired coagulation disorders, autoimmune diseases, abdominal infections/ inflammations, abdominal intervention, transplantation, cirrhosis, and malignancies [11-24]. In this study, the predominant risk factor was HCC (52.5\%), followed by liver cirrhosis without cancer (9.3\%), and abdominal infections/inflammations (9.3\%). Although HCC has been reported as a risk factor for PVT in the Caucasian patients [20], the prevalence was not as high as in the Asian cases. A high prevalence of HCC-associated PVT was noted in several series requiring therapeutic interventions in Chinese patients [14,23]. Cirrhosis without cancer was, in contrast, reported at a higher percentage as a cause of PVT than our cases. In a study of 172 PVT cases from the Netherlands, 15 cases of HCC and 37 cases of cirrhosis were reported, which represented $8.7 \%$ and $21.5 \%$ of the total cases, respectively [16]. A study from Sweden also reported that HCC and cirrhosis without cancer could be identified in $23 \%$ and $28 \%$ of the 254 PVT cases, respectively, although the exact etiologies of cirrhosis and HCC were not delineated in either study [1]. Our results, however, were as expected with respect to the natural history of cirrhosis and HCC and its relationship to thrombosis. Increasing incidence of PVT was observed in patients with liver decompensation and HCC when compared to patients with wellcompensated cirrhosis $[3,17,25]$.

The most common cause of cirrhosis in this patient cohort was HBV infection $(38 / 98,38.8 \%)$ which was much more prevalent than HCV infection (12/98, $12.2 \%)$. Alcohol was also the frequent cause of cirrhosis (15/98, 15.3\%), and the combination of HBV, HCV and alcohol was found in 11 cases $(11.2 \%)$. Patients without cirrhosis or $\mathrm{HCC}$ had a very low incidence of $\mathrm{HBV}$ or $\mathrm{HCV}$ infection. Our study is unique in that the majority of our PVT cases with underlying cirrhosis and HCC were associated with chronic HBV infection. HCV infection was not as prevalent as HBV infection alone as the cause of PVT which could be explained by the strikingly low incidence of HCV infection in the Southeast Asian population as compared to the Western populations $[26,27]$. Moreover, alcohol was the most common risk factor for $\mathrm{HCC}$ in a series reported from the United States [20]. Although HBV vaccination program has been implemented for all neonates in Thailand since 1992 , the majority of our older generation is still not immunized and at least 4-8\% of the population continues to be affected by the infection $[26,28,29]$. It is thus likely that HBV-associated cirrhosis/HCC will continue to be the major risk factor of PVT in the next few decades.
The risk factors of PVT appeared to vary according to age and gender. In young patients aged $<20$ years, umbilical catheterization was the main risk which was similar to the study of 31 children with PVT in Italy [30], whereas in older adults (age 40-60 and >60), malignancy was the major etiology (69.1\% and $86 \%$, respectively). Only 1 case of cancer, i.e. hepatoblastoma, was found in a young patient with PVT. Abdominal infection such as omphalitis which causes thrombophlebitis of the umbilical vein and eventually the portal system was reported in most pediatric series $[21,31]$ but was found in only 1 case in this study (7.7\%). Almost half of our young patients had unidentifiable risks (46.2\%) which could be attributed to truly idiopathic causes or incomplete thrombophilic investigations. Although the main limitation of this study is its retrospective nature and a complete set of thrombophilic investigations might not have been performed in some of these cases in the last 10 years, it should be noted that hereditary thrombophilic disorders such as Factor V Leiden, prothrombin gene G20210A mutation, protein C deficiency, protein S deficiency, antithrombin deficiency, and methylenetetrahydrofolate reductase (MTFR) gene mutation are very rare in the Southeast Asian population [32,33]. A study of 61 patients with PVT from India reported only 1 case of Factor V Leiden and none with prothrombin gene G20210A mutation [34]. A prospective study should be performed to further explain these unidentifiable causes. Regarding the impact of gender, men were more commonly affected with cirrhosis and malignancies than women although both conditions remained the major risk factors in both genders.

Several risk factors identified in this population have rarely been described and are remarkably different from reports from the Western countries. Tuberculosis which is a prevalent infection in the Southeast Asia region was also found associated with PVT although abdominal tuberculosis is not a common manifestation [6]. In this study, a 32-year-old man who was previously diagnosed with abdominal tuberculosis came to our hospital because of hematemesis, melena, and splenomegaly. Endoscopic studies showed esophago-gastric varices with portal-hypertensive-gastropathy and CT scan of the whole abdomen revealed PVT. Two single cases of rare malformation syndromes such as Klippel-Trénaunay vascular malformation syndrome [9] and systemic lymphangiomatosis [10], which had been sporadically reported, were also discovered in our series. As for the first case, a 25-year-old woman came to the hospital because of epigastric pain radiating to midback associated with nausea and vomiting. The patient had splenomegaly and lymphadenopathy and CT study of the whole abdomen showed portal-spleno-mesenteric vein 
thrombosis with multiple cysts in the liver, pancreas, and spleen. A lymph node biopsy revealed lymphangioma; therefore this patient was diagnosed with systemic lymphangiomatosis with PVT which is the first case ever reported from the Southeast Asian population. The second case was a 29-year-old man with KlippelTrénaunay syndrome who came to the hospital because of epigastric pain radiating to midback and was found to have an enlarged spleen on examination. He was subsequently found to have portal-spleno-mesenteric vein thrombosis by $\mathrm{CT}$ imaging. This case also represents the first case of Klippel-Trénaunay syndrome associated with PVT ever reported from the Southeast Asian region.

Bone marrow disorders such as paroxysmal nocturnal hemoglobinuria $(\mathrm{PNH})$ and myeloproliferative neoplasms (MPN) including polycythemia vera (PV), chronic myeloid leukemia (CML), essential thrombocytosis (ET), and primary myelofibrosis (PMF) have been reported as presenting causes of abdominal venous thrombosis. In this study, we were able to identify only 2 cases of PNH-associated PVT among 497 medical charts extracted during a 10-year study period, supporting that venous thrombosis is rare in the PNH patients in Thailand [35] as contrast to the Western series [36]. Moreover, MPN which was found as a potential risk for PVT in the Western series necessitating a bone marrow study, endogenous erythroid colony (EEC) culture, and a $J A K 2$ mutation analysis was infrequently identified in this cohort [24,37]. Only 3 cases of PV, 2 cases of PMF and 1 case of ET were discovered.

Other types of malignancies associated with PVT were also examined. In this study, secondary malignant tumors of the liver were identified in only 2 cases (1\%). This frequency was much lower than the report by the Swedish autopsy series which found 111 PVT cases (44\% of 254 cases) with secondary malignancy of the hepatobiliary region, and the major cause of which was pancreatic carcinoma (42\%) [1]. The differences could be due to the fact that most autopsy series often revealed more occult cases of malignancies at the time of death than the clinical case reports performed while the patients still alive. Nevertheless, it could be concluded that metastatic cancer to the liver is an uncommon risk factor of PVT in this study. It is of interest to identify CCA as the second most common type of cancer associated with PVT in our population (16 cases, $8.2 \%)$. CCA is a rare cancer in the West but its prevalence is very high in Thailand and neighboring countries, the cause of which is mainly associated with Opisthorchis viverrini infection $[38,39]$.

The clinical presentations of PVT patients in this study were typical of portal hypertension as a result of portal vein occlusion. A study from India performed in children younger than 14 years old showed that in the developing countries, $73 \%$ of extrahepatic portal hypertension were caused by PVT [8]. Splenomegaly which was the dominant clinical presentation in our patients without cancer and cirrhosis was consistent with the Danish's report [6]. However, most of our patients with cancer or cirrhosis had a slightly different presentation from those without cancer or cirrhosis since more cases in the first group presented with abdominal pain and ascites while the latter presented with splenomegaly. It could be argued that the abdominal pain symptom could be the result of HCC involvement of the liver, rather than PVT, however, it was too difficult to differentiate one another from the medical records.

It was of interest to find that $\mathrm{CT}$ was the most popular imaging modality for PVT diagnosis in this series. In general, Doppler ultrasonography is a preferred screening tool to diagnose thrombus in the portal system due to its lower costs, lack of need for intravenous contrast material injection, and ease of multiple follow-up examinations $[40,41]$. However, its sensitivity is operatordependent which can vary from $60 \%$ to $100 \%$ [6,42-44]. CT has become widely available in Thailand for many years and it could be speculated that $\mathrm{CT}$ was performed in the majority of patients in this series (139 cases, $71.6 \%$ ) because physicians felt that it was more accurate and more informative than ultrasonography to confirm the presence and extent of thrombus as well as to identify various abdominal etiologies associated with PVT [45]. MRI is another modality that can be used for PVT diagnosis with a high accuracy although its true sensitivities and specificities have never been reported for PVT diagnosis [46]. MRI was utilized only in a few patients in this series (9 cases, $4.6 \%$ ) due to its limited availability and associated higher costs than $\mathrm{CT}$ and ultrasonography.

With respect to the sites of thrombus formation, it was of interest to find that the main branch was commonly affected in the younger patients whereas the right branch was slightly more affected than the left branch in the older patients. The reason why thrombi occur in different branches of the portal system in young and older patients remains unclear. However, with respect to the most common distribution of thrombus in patients with cancer and cirrhosis, our results were in agreement with a previous finding from Italy which revealed that among 701 patients with liver cirrhosis, the thrombus was found most commonly in the main portal trunk [3]. Moreover, a study from China also showed that the right branch was the most commonly affected branch in a series of 108 patients with advanced HCC [47].

\section{Conclusion}

One hundred and ninety-four cases of PVT were identified in a 10-year study period. The predominant 
identifiable risk factor was chronic HBV infection which is prevalent in this region and is strongly associated with cirrhosis and HCC. Interaction of host and environmental factors may play an important role in the pathogenesis of PVT in various ethnic populations residing in heterogeneous geographic regions. Future prospective studies such as gene association studies should be performed in order to identify the genetic risks and their modifying factors for PVT in these populations.

\section{Acknowledgements}

CUA is the current recipient of the Faculty Development Award from Siriraj Chalermprakiat Fund. A financial support from the Faculty of Medicine Siriraj Hospital Research and Development Grant and Siriraj Foundation is greatly appreciated.

\section{Authors' contributions}

$\mathrm{KL}$ was responsible for data collection and analysis and drafting of the manuscript. CUA was KL's major advisor who was responsible for the initiation and the execution of the project and the critical revision of the manuscript. Both authors read and approved the final manuscript.

\section{Competing interests}

The authors declare that they have no competing interests.

Received: 25 February 2011 Accepted: 10 June 2011

Published: 10 June 2011

\section{References}

1. Ogren M, Bergqvist D, Bjorck M, Acosta S, Eriksson H, Sternby NH: Portal vein thrombosis: prevalence, patient characteristics and lifetime risk: a population study based on 23,796 consecutive autopsies. World J Gastroenterol 2006, 12:2115-2119.

2. Hoekstra J, Janssen HL: Vascular liver disorders (II): portal vein thrombosis. Neth J Med 2009, 67:46-53.

3. Amitrano L, Guardascione MA, Brancaccio V, Margaglione M, Manguso F, lannaccone L, Grandone E, Balzano A: Risk factors and clinical presentation of portal vein thrombosis in patients with liver cirrhosis. $J$ Hepatol 2004, 40:736-741

4. DeLeve LD, Valla DC, Garcia-Tsao G: Vascular disorders of the liver. Hepatology 2009, 49:1729-1764.

5. Poddar U, Thapa BR, Rao KL, Singh K: Etiological spectrum of esophageal varices due to portal hypertension in Indian children: is it different from the West? J Gastroenterol Hepatol 2008, 23:1354-1357.

6. Sogaard KK, Astrup LB, Vilstrup H, Gronbaek H: Portal vein thrombosis; risk factors, clinical presentation and treatment. BMC Gastroenterol 2007, 7:34.

7. Gaiani S, Bolondi L, Li Bassi S, Zironi G, Siringo S, Barbara L: Prevalence of spontaneous hepatofugal portal flow in liver cirrhosis. Clinical and endoscopic correlation in 228 patients. Gastroenterology 1991, 100:160-167.

8. Arora NK, Lodha R, Gulati S, Gupta AK, Mathur P, Joshi MS, Arora N, Mitra DK: Portal hypertension in north Indian children. Indian J Pediatr 1998, 65:585-591.

9. Kulungowski AM, Fox VL, Burrows PE, Alomari Al, Fishman SJ: Portomesenteric venous thrombosis associated with rectal venous malformations. J Pediatr Surg 45:1221-1227.

10. de Souza LM, Bentlin MR, de Abreu ES, Bacchi CE: Systemic congenital lymphangiomatosis. Sao Paulo Med J 1996, 114:1278-1281.

11. Aguas M, Bastida G, Nos P, Beltran B, Grueso JL, Grueso J: Septic thrombophlebitis of the superior mesenteric vein and multiple liver abscesses in a patient with Crohn's disease at onset. BMC Gastroenterol 2007, 7:22.

12. Condat B, Pessione F, Helene Denninger M, Hillaire S, Valla D: Recent Portal or Mesenteric Venous Thrombosis: Increased Recognition and Frequent Recanalization on Anticoagulant Therapy. Hepatology 2000, 32:466-470.

13. Egawa H, Tanaka K, Kasahara M, Takada Y, Oike F, Ogawa K, Sakamoto S, Kozaki K, Taira K, Ito T: Single center experience of 39 patients with preoperative portal vein thrombosis among 404 adult living donor liver transplantations. Liver Transp/ 2006, 12:1512-1518.

14. Fan J, Zhou J, Wu ZQ, Qiu SJ, Wang XY, Shi YH, Tang ZY: Efficacy of different treatment strategies for hepatocellular carcinoma with portal vein tumor thrombosis. World I Gastroenterol 2005, 11:1215-1219.

15. Huang JW, Wu MS, Chu TS, Tsai TJ: Hepatic aneurysm and portal vein thrombosis in a patient with lupus erythematosus on dialysis. Nephrol Dial Transplant 1999, 14:753-756.

16. Janssen $H L$, Wijnhoud A, Haagsma EB, van Uum SH, van Nieuwkerk CM, Adang RP, Chamuleau RA, van Hattum J, Vleggaar FP, Hansen BE, et al: Extrahepatic portal vein thrombosis: aetiology and determinants of survival. Gut 2001, 49:720-724.

17. Okuda K, Ohnishi K, Kimura K, Matsutani S, Sumida M, Goto N, Musha H, Takashi M, Suzuki N, Shinagawa T, et al: Incidence of portal vein thrombosis in liver cirrhosis. An angiographic study in 708 patients. Gastroenterology 1985, 89:279-286.

18. Orloff MJ, Orloff MS, Orloff SL, Girard B: Portal vein thrombosis in cirrhosis with variceal hemorrhage. J Gastrointest Surg 1997, 1:123-130, discussion 130-121.

19. Plemmons RM, Dooley DP, Longfield RN: Septic thrombophlebitis of the portal vein (pylephlebitis): diagnosis and management in the modern era. Clin Infect Dis 1995, 21:1114-1120.

20. Stuart KE, Anand AJ, Jenkins RL: Hepatocellular carcinoma in the United States. Prognostic features, treatment outcome, and survival. Cancer 1996, 77:2217-2222.

21. Webb LJ, Sherlock S: The aetiology, presentation and natural history of extra-hepatic portal venous obstruction. Q J Med 1979, 48:627-639.

22. Yoshida M, Watanabe $Y$, Horiuchi A, Yamamoto $Y$, Sugishita H, Kawachi $K$ : Portal and splenic venous thrombosis after splenectomy in patients with hypersplenism. Hepatogastroenterology 2009, 56:538-541.

23. Zhang XB, Wang JH, Yan ZP, Qian S, Du SS, Zeng ZC: Hepatocellular carcinoma with main portal vein tumor thrombus: treatment with 3dimensional conformal radiotherapy after portal vein stenting and transarterial chemoembolization. Cancer 2009, 115:1245-1252.

24. Plessier A, Darwish-Murad S, Hernandez-Guerra M, Consigny Y, Fabris F, Trebicka J, Heller J, Morard I, Lasser L, Langlet P, et al: Acute portal vein thrombosis unrelated to cirrhosis: a prospective multicenter follow-up study. Hepatology 51:210-218.

25. Qi X, Bai M, Yang Z, Yuan S, Zhang C, Han G, Fan D: Occlusive portal vein thrombosis as a new marker of decompensated cirrhosis. Med Hypotheses

26. Beasley RP: Rocks along the road to the control of HBV and HCC. Ann Epidemiol 2009, 19:231-234

27. Dultz G, Kronenberger B, Azizi A, Mihm U, Vogl TJ, Sarrazin U, Sarrazin C, Zeuzem S, Hofmann WP: Portal vein thrombosis as complication of romiplostim treatment in a cirrhotic patient with hepatitis $\mathrm{C}$-associated immune thrombocytopenic purpura. J Hepatol.

28. Poovorawan Y, Chongsrisawat V, Theamboonlers A, Leroux-Roels G, Kuriyakose $\mathrm{S}$, Leyssen $\mathrm{M}$, Jacquet JM: Evidence of protection against clinical and chronic hepatitis B infection 20 years after infant vaccination in a high endemicity region. $J$ Viral Hepat .

29. Sa-Nguanmoo P, Tangkijvanich P, Thawornsuk N, Vichaiwattana P, Prianantathavorn K, Theamboonlers A, Tanaka Y, Poovorawan Y: Molecular epidemiological study of hepatitis B virus among migrant workers from Cambodia, Laos, and Myanmar to Thailand. J Med Virol 82:1341-1349.

30. Pietrobattista A, Luciani M, Abraldes JG, Candusso M, Pancotti S, Soldati M, Monti L, Torre G, Nobili V: Extrahepatic portal vein thrombosis in children and adolescents: Influence of genetic thrombophilic disorders. World J Gastroenterol 16:6123-6127.

31. Kameda H, Yamazaki K, Imai F, Sugiura M, Nakashima T, Okuda K, The Japanese Ministry Of Health Welfare Research Committee On Idiopathic Portal H: Obliterative portal venopathy: A comparative study of 184 cases of extrahepatic portal obstruction and 469 cases of idiopathic portal hypertension. Journal of Gastroenterology and Hepatology 1986, 1:139-149

32. Angchaisuksiri $P$, Atichartakarn $V$, Aryurachai $K$, Archararit N, Rachakom $B$ Atamasirikul K, Tiraganjana A: Risk factors of venous thromboembolism in thai patients. Int I Hematol 2007, 86:397-402.

33. Sirachainan N, Chuansumrit A, Angchaisuksiri P, Pakakasama S, Hongeng S, Kadegasem P: Venous thromboembolism in Thai children. Pediatr Hematol Oncol 2007, 24:245-256. 
34. Sharma S, Kumar SI, Poddar U, Yachha SK, Aggarwal R: Factor V Leiden and prothrombin gene G20210A mutations are uncommon in portal vein thrombosis in India. Indian J Gastroenterol 2006, 25:236-239.

35. Kruatrachue M, Wasi P, Na-Nakorn S: Paroxysmal nocturnal haemoglobinuria in Thailand with special reference to as association with aplastic anaemia. Br J Haematol 1978, 39:267-276.

36. Rosse WF, Nishimura J: Clinical manifestations of paroxysmal nocturnal hemoglobinuria: present state and future problems. Int J Hematol 2003, 77:113-120.

37. Kannim S, Auewarakul CU: The impact of JAK2 non-receptor tyrosine kinase mutation on the mobilization of hematopoietic stem cells into peripheral blood of patients with Philadelphia chromosome-negative myeloproliferative disorders. Int J Cancer 2009, 125:988-990.

38. Kurathong S, Lerdverasirikul P, Wongpaitoon V, Pramoolsinsap C, Kanjanapitak A, Varavithya W, Phuapradit P, Bunyaratvej S, Upatham ES, Brockelman WY: Opisthorchis viverrini infection and cholangiocarcinoma. A prospective, case-controlled study. Gastroenterology 1985, 89:151-156.

39. Shin HR, Oh JK, Masuyer E, Curado MP, Bouvard V, Fang Y, Wiangnon S, Sripa B, Hong ST: Comparison of Incidence of Intrahepatic and Extrahepatic Cholangiocarcinoma - Focus on East and South-eastern Asia. Asian Pac J Cancer Prev 11:1159-1166.

40. Gertsch P, Matthews J, Lerut J, Luder P, Blumgart LH: Acute thrombosis of the splanchnic veins. Arch Surg 1993, 128:341-345.

41. Miller VE, Berland LL: Pulsed Doppler duplex sonography and CT of portal vein thrombosis. AJR Am J Roentgenol 1985, 145:73-76.

42. Parvey HR, Eisenberg RL, Giyanani V, Krebs CA: Duplex sonography of the portal venous system: pitfalls and limitations. AJR Am J Roentgenol 1989, 152:765-770.

43. Tessler FN, Gehring BJ, Gomes AS, Perrella RR, Ragavendra N, Busuttil RW, Grant EG: Diagnosis of portal vein thrombosis: value of color Doppler imaging. AJR Am J Roentgenol 1991, 157:293-296.

44. Chawla Y, Duseja A, Dhiman RK: Review article: the modern management of portal vein thrombosis. Aliment Pharmacol Ther 2009, 30:881-894.

45. Haddad MC, Clark DC, Sharif HS, al Shahed M, Aideyan O, Sammak BM: MR, $\mathrm{CT}$, and ultrasonography of splanchnic venous thrombosis. Gastrointest Radiol 1992, 17:34-40.

46. Zirinsky K, Markisz JA, Rubenstein WA, Cahill PT, Knowles RJ, Auh YH, Morrison $\mathrm{H}$, Kazam $\mathrm{E}$ : MR imaging of portal venous thrombosis: correlation with CT and sonography. AJR Am J Roentgenol 1988, 150:283-288.

47. Lu ZH, Shen F, Yan ZL, Li J, Yang JH, Zong M, Shi LH, Wu MC: Treatment of portal vein tumor thrombus of hepatocellular carcinoma with percutaneous laser ablation. J Cancer Res Clin Oncol 2009, 135:783-789.

Pre-publication history

The pre-publication history for this paper can be accessed here: http://www.biomedcentral.com/1471-230X/11/66/prepub

doi:10.1186/1471-230X-11-66

Cite this article as: Lertpipopmetha and Auewarakul: High Incidence of Hepatitis B Infection-Associated Cirrhosis and Hepatocellular Carcinoma in the Southeast Asian Patients with Portal Vein Thrombosis. BMC Gastroenterology 2011 11:66.

\section{Submit your next manuscript to BioMed Central and take full advantage of:}

- Convenient online submission

- Thorough peer review

- No space constraints or color figure charges

- Immediate publication on acceptance

- Inclusion in PubMed, CAS, Scopus and Google Scholar

- Research which is freely available for redistribution

Submit your manuscript at www.biomedcentral.com/submit
Biomed Central 